\title{
SPECTROSCOPIC STUDIES OF AMINOACIDS COMPLEXES WITH BIOMETALS
}

\author{
Andreea Stanila, Sorin Stanila \\ Agricultural Science and Veterinary Medicine University., 400372 Cluj-Napoca, Romania \\ andreea7s@yahoo.com
}

\begin{abstract}
The $\left[\mathrm{Cu}(\mathrm{L})_{2}\right] \cdot \mathrm{H}_{2} \mathrm{O},\left[\mathrm{Co}(\mathrm{L})_{2}\right] \cdot 2 \mathrm{H}_{2} \mathrm{O},\left[\mathrm{Zn}(\mathrm{L})_{2}\right] \cdot \mathrm{H}_{2} \mathrm{O}$ complexes with methionine $(\mathbf{L})$ as ligand, were synthesized in water solution and analyzed by means of: elemental analysis, atomic absorption spectroscopy, thermogravimetry, FT-IR, UV-VIS and EPR spectroscopies.

The atomic absorption spectroscopy and elemental measurements confirm the ratio 1:2 metal ion: methionine composition for the synthesised compounds. The IR spectra show that amino acids act as bidentate ligands with coordination involving the carboxylic oxygen and the nitrogen atom of the amino group. Spectral UV-VIS data confirmed the covalent metal-ligand bonds, the pseudotetrahedral symmetry around the copper and zinc ions and the octahedral environment for the cobalt ion. Powder ESR spectra at room temperature are typically for monomeric species.
\end{abstract}

Key words: biometals complexes, methionine, DSC, spectroscopies

\section{Introduction}

Minerals such as zinc, copper, iron and others can chemically bond to amino acids resulting chelates. Amino acids are ideal chelators or ligands from both chemical [1] and nutritional [2] points of view. Metal amino acid chelates resemble these compounds which allow the minerals to be carried in with the amino acids during absorption. Finally, the amino acids, once released from the metal, can be used to build proteins or provide energy.

The metabolism of sulfur amino acids, methionine has been linked to several key aspects of human health and cellular function [2]. Methionine (Fig.1) is the only sulfur-containing amino acid that is essential for mammals and must therefore be derived entirely from the diet. In contrast, methionine is synthesized by plants and most microorganisms after the initial steps of inorganic sulfate assimilation and cysteine or homocysteine syntheses [3-6]. A preliminary study has suggested that methionine (6 grams per day) may improve memory recall in people with AIDS-related nervous system degeneration [7] and also may help treat some symptoms of Parkinson's disease [8].

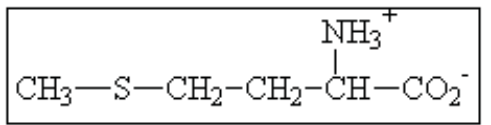

Fig.1. Methionine structural formula

\section{Experimental}

\subsection{Physical-Chemical Measurements}

The Vario El device allows the quantitative determination of the carbon, nitrogen, hydrogen, sulphur and oxygen in various operating modes. Atomic absorption measurements were realized with an AAS- 1 device at $\lambda=320 \mathrm{~nm}$ wavelength. The Differential scanning calorimetry measurements were carried out with a Mettler Toledo device, with $10^{\circ} \mathrm{C} /$ minute heating rate until a $500^{\circ} \mathrm{C}$ temperature was reached. The samples weights were between 1 and $2.5 \mathrm{mg}$. FTIR spectra were taken with a Perkin-Elmer FT-IR 1730 spectrophotometer over $\mathrm{KBr}$ solid samples in $4000-400 \mathrm{~cm}^{-1}$ range. UV and visible electronic spectra were recorded in the $\lambda=190-1100 \mathrm{~nm}$ range in aqueous solution $\left(10^{-5} \mathrm{M}\right)$ for threonine, copper and cobalt complexes and in ethanol solution for the zinc complex, using a standard Jasco V-530 spectrophotometer.

Powder EPR measurements were performed at room temperature at $9.56 \mathrm{GHz}$ (X band) using a standard JEOLJES-3B equipment.

\subsection{Synthesis of the complexes}

The purpose of the study was to obtain neutral complexes of $\mathbf{M L}_{2} \cdot \mathbf{n} \mathbf{H}_{2} \mathbf{O}$ type $(\mathrm{M}=\mathrm{Cu}, \mathrm{Co}, \mathrm{Zn})$ at $\mathrm{pH}=8-10$, in the presence of a strong basis $(\mathrm{NaOH})$ to obtain the ionisation conditions of the amino acid.

The complexes were prepared following the next procedure: $2 \mathrm{mmol}$ of the methionine $(0,286 \mathrm{~g})$ were dissolved in $5 \mathrm{ml}$ warm distilled water. For the deprotonation of the amino acid $0.33 \mathrm{ml} 30 \% \mathrm{NaOH}$ was added.

For all the complexes the precipitation was instantaneous, and a grey-blue precipitate was obtained $(\eta=99.8 \%)$ for $\mathbf{1}$, a pink one for $\mathbf{2}(\eta=72.7 \%)$ and a white one for $\mathbf{3}(\eta=75.7 \%)$. The complexes were filtered, washed with ethanol and dried in desiccators under $\mathrm{P}_{4} \mathrm{O}_{10}$. Then, the complexes were recrystallized on methanol, dried and weight to establish the percent of complexation. 


\section{Results and Discussions}

\subsection{Elemental analysis}

The elemental analysis results for the synthesized complexes confirm the 1:2 ratio metal/ methionine. The elemental analysis data of the metal-methionine complexes are pointed up in Table 2.

Table 1

Elemental analysis results the complexes

\begin{tabular}{|l|c|c|c|c|c|c|c|c|c|}
\hline \multirow{2}{*}{ Symbolic formula } & \multirow{2}{*}{$\begin{array}{c}\text { Molecular } \\
\text { weight }\end{array}$} & \multicolumn{2}{|c|}{$\% \mathbf{C}$} & \multicolumn{2}{|c|}{$\% \mathbf{H}$} & \multicolumn{2}{c|}{$\% \mathbf{N}$} & \multicolumn{2}{c|}{$\%$ Metal } \\
\cline { 3 - 10 } & & Calc. & Meas. & Calc. & Meas. & Calc. & Meas. & Calc. & Meas. \\
\hline$\left[\mathrm{Cu}(\mathrm{L})_{2}\right] \cdot \mathrm{H}_{2} \mathrm{O}$ & 357.5 & 33.56 & 31.50 & 5.5 & 5.72 & 7.8 & 7.27 & 17.9 & 17.26 \\
\hline$\left[\mathrm{Co}(\mathrm{L})_{2}\right] \cdot 2 \mathrm{H}_{2} \mathrm{O}$ & 353 & 33.59 & 30.75 & 5.66 & 6.21 & 7.93 & 7.41 & 18.13 & 17.76 \\
\hline$\left[\mathrm{Zn}(\mathrm{L})_{2}\right] \cdot \mathrm{H}_{2} \mathrm{O}$ & 359.6 & 33.39 & 33.14 & 5.56 & 6.33 & 7.69 & 6.74 & 17.81 & 16.19 \\
\hline
\end{tabular}

\subsection{Atomic absorption spectroscopy}

The atomic absorption results for the synthesized complexes are in concordance to those theoretical obtained (Table 2).

Metal concentrations obtained by means of atomic spectroscopy
\begin{tabular}{|l|c|c|}
\hline Complex & Metal concentration from the complex (\%) \\
\cline { 2 - 3 } & Calc. & Meas. \\
\hline $\mathbf{1}$ & 17.44 & 17.43 \\
\hline $\mathbf{2}$ & 16.05 & 15.77 \\
\hline $\mathbf{3}$ & 15.66 & 16.47 \\
\hline
\end{tabular}

Table 2

\subsection{Differential Scanning Calorimetry}

The differential scanning calorimetry advantages are owed to the direct measurement of the intrinsec thermal properties of the sample and are not invasive and do not need chemical conversion [10]. complexes.

Differential scanning calorimetry (DSC) was used for a qualitative interpretation of the synthesized

The ligand trace indicate an endothermic reaction at $275{ }^{\circ} \mathrm{C}$ specific to pure substances and an exothermic reaction between 310 to $360^{\circ} \mathrm{C}$ attributed to the decomposition and combustion of organic matter components. The thermogram of complex 1 indicates a melting process fallowed by decomposition between 230 to $270{ }^{\circ} \mathrm{C}$ and the several exothermic peaks between 270 to $420^{\circ} \mathrm{C}$ are attributable to the oxidation of the decomposing product. The complete combustion took place subsequent to $500^{\circ} \mathrm{C}$. The complex 2 thermogram indicates a more complex plot with peaks owing to dehydration, decomposition, oxidation and combustion processes. Between 80 to $100{ }^{\circ} \mathrm{C}$ two successive endothermic peaks appeared and were attributed to dehydration processes. After $100{ }^{\circ} \mathrm{C}$ a two step decomposition processes took place between 130 to $200^{\circ} \mathrm{C}$ and 150 to $170^{\circ} \mathrm{C}$, and an intermediary product was formed. The exothermic from $380^{\circ} \mathrm{C}$ and $400^{\circ} \mathrm{C}$ were associated to the oxidation of the decomposing products. The complete combustion took place subsequent to $480{ }^{\circ} \mathrm{C}$. The DSC trace of complex 3 indicates an exothermic reaction between 130 to $150{ }^{\circ} \mathrm{C}$ attributed to the crystallization process. The melting point appears at lower temperature $\left(220^{\circ} \mathrm{C}\right)$ than the one for the ligand $\left(275^{\circ} \mathrm{C}\right)$, which profs the complex formation. The complete combustion took place subsequent to $450{ }^{\circ} \mathrm{C}$. The DSC trace for all samples are given in Fig. 1.

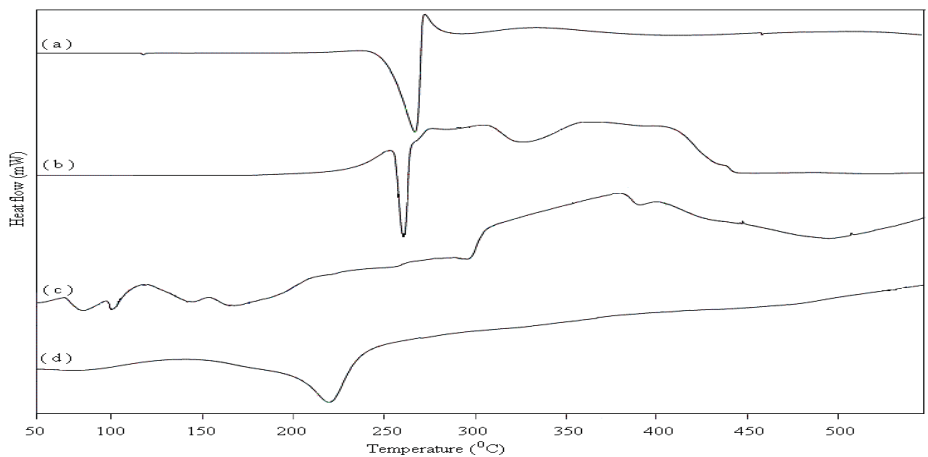

Fig 2. DSC thermograms of L (a), 1 (b), 2 (c) and 3(d) 


\subsection{FT-IR spectroscopy}

In the figure (Fig.3) the main parts of the IR spectra are presented and most important absorption bands and their assignments are shown in Table 3.

In the ligand spectra the $v(\mathrm{~N}-\mathrm{H})$ stretching vibration appears at $3146 \mathrm{~cm}^{-1}$ and is shifted at $3229 \mathrm{~cm}^{-1}, 3172$ $\mathrm{cm}^{-1}$ and $3450 \mathrm{~cm}^{-1}$ in the $\mathrm{Cu}(\mathrm{II}), \mathrm{Co}(\mathrm{II})$ and $\mathrm{Zn}$ (II) spectra proving the involvement of the $-\mathrm{NH}_{2}$ - group in the complex formation [11-13]. The $\mathrm{CH}_{2}-\mathrm{S}$ and $\mathrm{CH}_{3}-\mathrm{S}$ stretching vibrations appears as a sharp band at $2915 \mathrm{~cm}^{-1}$ in the ligand spectrum and are insignificant shifted in the complexes spectra confirming the non involvement to the coordination. The absorption band from $1610 \mathrm{~cm}^{-1}$ in the ligand spectrum was attributed to the $v(\mathrm{C}=\mathrm{O})$ stretching vibration and appears to be shifted toward higher wave numbers in the complexes $\mathbf{1}$ and $\mathbf{2}$ spectra, which involves the carboxylic group in the covalent bonding to the metal ion [14]. The $v(\mathrm{OH})$ stretching vibrations do not emerge in the ligand spectrum, but they appear in the complexes spectra at values between 3383 to $3449 \mathrm{~cm}^{-1}$, suggesting the presence of the crystallisation water within these complexes.

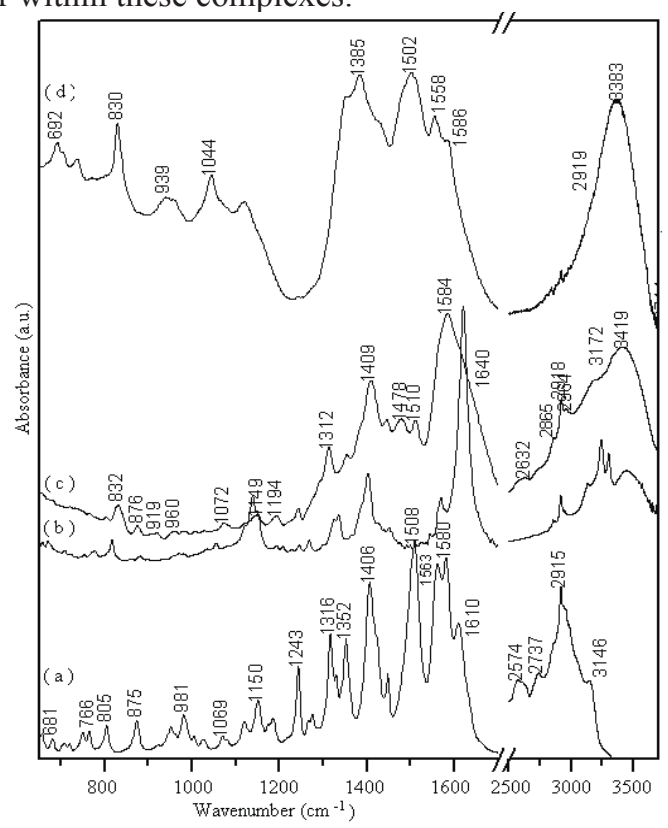

Table 3

FT-IR spectral data $\left(\mathrm{cm}^{-1}\right)$

\begin{tabular}{lcccc}
\hline Band & $\mathbf{L}$ & $\mathbf{1}$ & $\mathbf{2}$ & $\mathbf{3}$ \\
\hline $\mathbf{v}(\mathbf{N}-\mathbf{H})$ & 3146 & 3229 & 3172 & 3450 \\
$\mathbf{v}(\mathbf{O}-\mathbf{H})$ & - & 3449 & 3419 & 3383 \\
& & & & \\
$\mathbf{v}(\mathbf{C}=\mathbf{O})$ & 1610 & 1640 & 1640 & 1586 \\
& & & & \\
$\boldsymbol{\delta}_{\mathbf{s}}(\mathbf{N}-\mathbf{H})$ & 1580 & 1568 & 1584 & 1502 \\
& 1563 & 1616 & & 1558 \\
& 1508 & & & \\
\hline
\end{tabular}

Fig. 3. FT-IR spectra of $\mathbf{L}$ (a), 1 (b), 2 (c) and $\mathbf{3}$ (d)

\subsection{UV-VIS Spectroscopy}

The local symmetry around the metallic ions was determined comparing the amino acid and metallic complexes UV-VIS spectra [14].

The $n \rightarrow \pi^{*}$ characteristic band in the UV spectra assigned to the $\mathrm{C}=\mathrm{O}$ bond appear at $267 \mathrm{~nm}$ for threonine (Fig.3.a) and is shifted toward higher wave lengths with $8 \mathrm{~nm}, 7 \mathrm{~nm}$ and $2 \mathrm{~nm}$ for $\mathbf{1 , 2}$ respectively 3 confirming the presence of the ligand in the complex [15] and the covalent nature of the metal-ligand bond. In the visible domain (Fig.4) a d-d transition appears between at $625 \mathrm{~nm}$ in the copper complex spectrum assigned to the ${ }^{2} \mathrm{~T}_{2 \mathrm{~g}} \rightarrow{ }^{2} \mathrm{E}_{\mathrm{g}}$ transition, specific for $\mathrm{Cu}$ (II) complexes with tetragonal distortion owing to the Jahn-Teller effect. In the visible domain, the Co-L spectrum shows a band at $512 \mathrm{~nm}$ attributed to the $d-d$ transition of cobalt electrons. Based on the $\mathrm{d}^{7}$ diagram in $\mathrm{Oh}$ field the fallowing attribution were maid: $v_{1}=8100 \mathrm{~cm}^{-14} \mathrm{~T}_{2 \mathrm{~g}}(\mathrm{~F}) \rightarrow{ }^{4} \mathrm{~T}_{1 \mathrm{~g}}(\mathrm{~F}), v_{2}=16000 \mathrm{~cm}^{-1}{ }^{4} \mathrm{~A}_{2 \mathrm{~g}}(\mathrm{~F}) \rightarrow{ }^{4} \mathrm{~T}_{1 \mathrm{~g}}(\mathrm{~F}), v_{3}=19400 \mathrm{~cm}^{-1}$ ${ }^{4} \mathrm{~T}_{1 \mathrm{~g}}(\mathrm{P}) \rightarrow{ }^{4} \mathrm{~T}_{1 \mathrm{~g}}(\mathrm{~F})$. The last band within the spectrum was assigned to the ${ }^{4} \mathrm{~T}_{1 \mathrm{~g}}(\mathrm{P}) \rightarrow{ }^{4} \mathrm{~T}_{1 \mathrm{~g}}(\mathrm{~F})$ transition, expected for an octahedral symmetry of cobalt ion.
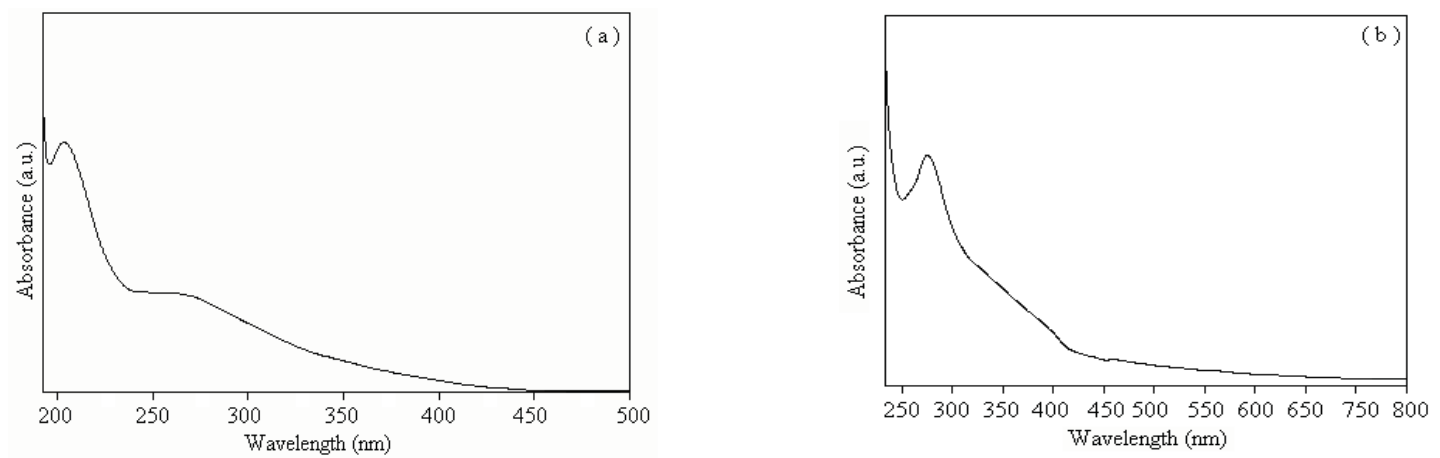

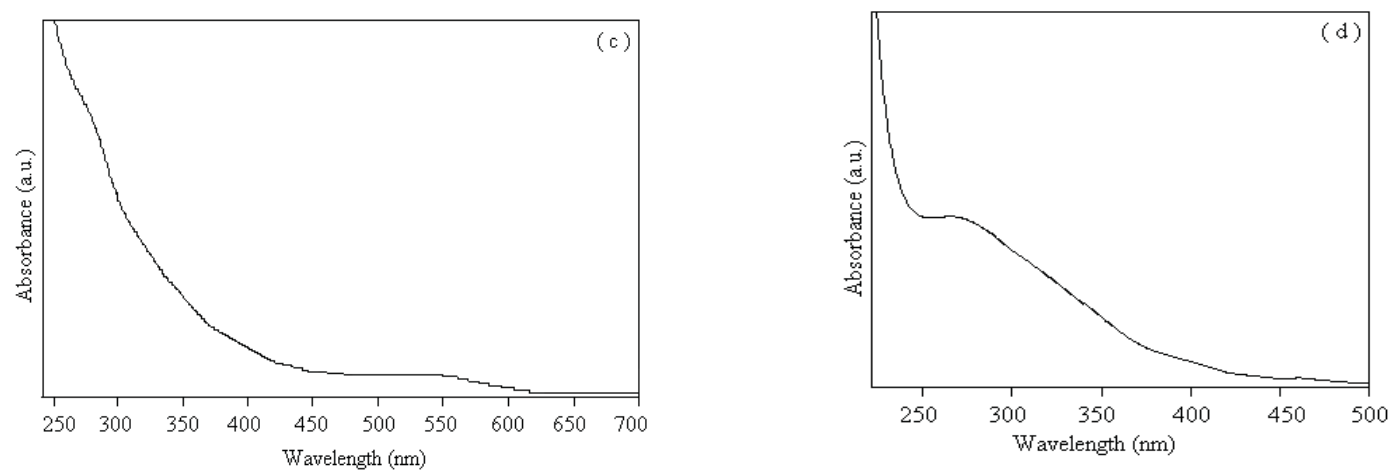

Fig. 4. UV and VIS spectra of $\mathbf{L}$ (a), 1 (b), 2 (c) and $\mathbf{3}$ (d)

\subsection{EPR Spectroscopy}

Powder EPR spectrum at room temperature are typically for pseudotetrahedral symmetry around the copper ion with the $g$ tensor value: $\mathrm{g}=2.094$ corresponding to $\mathrm{CuN}_{2} \mathrm{O}_{2}$ cromophore $[16,17]$. The Co-L powder EPR spectrum revealed the presence of monomeric compounds, with octahedral symmetry around the cobalt ion, the $\mathrm{g}$ tensor value is $\mathrm{g}=2.201[18]$.

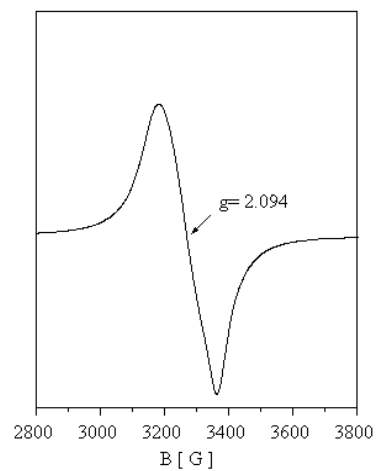

Fig. 5. Powder ESR spectrum of complex 1

\section{Conclusions}

Three new metallic complexes with methionine as ligand were synthesized and analyzed by means of: elemental analysis, atomic absorption, IR, UV-VIS and EPR spectroscopies.

The study reason was to compare the complexation capacity of the amino acids with the copper ion in similar synthesized conditions to choose those complexes which are easy to synthesize, with high yield, to use it as a method of extraction and separation of the amino acids from mixtures.

The atomic absorption spectroscopy and elemental analysis confirms the stoichiometry of the compounds, the composition corresponded to a metal-ligand ratio of 1:2. The IR spectra show that amino acids act as bidentate ligands with the coordination involving the carbonyl oxygen and the nitrogen atom of amino group. The EPR spectra confirm the pseudotetrahedral local symmetry for copper ion and octahedral symmetry for cobalt ion.

The obtained structural data allow us to propose the molecular formulas for the studied metal complexes which are shown in Figure 6.
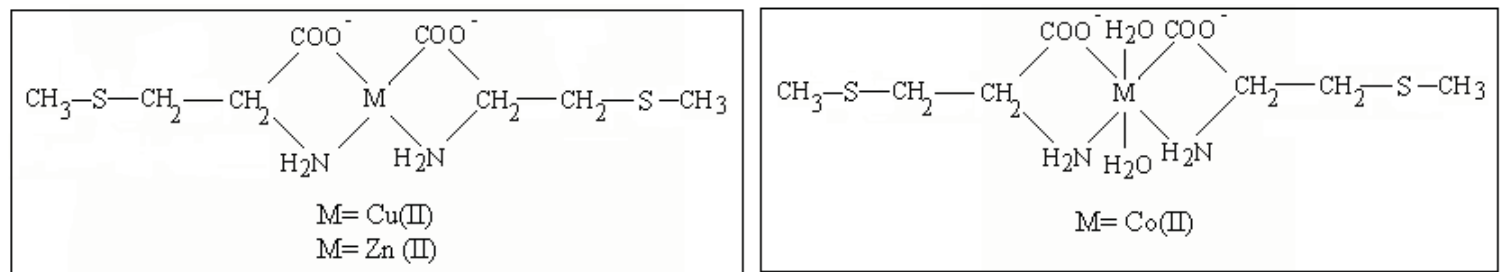

Fig. 6. Structural formulas proposed for the synthesized complexes 


\section{Acknowledgments}

This work was partially funded by National Research Grant IDEI no.1114/2009 financed by UEFISCDI-ROMANIA

\section{References}

[1]. R. Bentley, Biochemistry and Molecular Biology Edication, 33, 4, 274 (2005).

[2]. A. Shoveller, B. Stoll, R. Ball, D. Burrin, J. Nutr., 135, 7, 1609 (2005).

[3]. J. Giovanelli, Methods Ezymol., 143, 419 (1987).

[4]. I. Saint-Girons, C. Parsot,M. Zakin, O. Barzu, G. Cohen, Crit Rev Biochem, 23, 41 (1988).

[5]. G. Marzluf, Adv Genet., 31, 187 (1994).

[6]. D. Thomas, Y. Surdin-Kerjan, Microbiol Mol Biol Rev., 61, 503 (1997).

[7]. D. Dorfman, A. DiRocco, D. Simpson, AIDS, 11, 1066 (1997).

[8]. J. Smythies, J. Halsey, South Med. J., 77, 1577 (1984).

[9]. Niklas N., Wolf S., Anson K., Inorg. Chim. Acta, 2001, 314, 126-32;.

[10]. M. Pope, M. Judd, Differential Thermal Analysis, London, Academic Press, London (1977).

[11]. K. Burger, Coordination Chemistry: Experimental Methods, Akademiai Kiado, Budapesta (1973).

[12]. G. Socrates, Infrared and Raman Characteristic Group Frequencies: Tables and Charts, third edition, Wiley, Chichester, (2001).

[13]. L. J. Bellamy, The Infra-red Spectra of Complex Molecules, Wiley, New York (1975).

[14]. B. L.Silva, P. T. C. Freire, F. E. A Melo, I. Guedes, Araújo Silva, Mendes Filho, A. J. D Moreno, Brazilian Journal of Physics, 28, 19 (1998).

[15]. Alsfasser R., Hampel F., Niklas N., Clark T., Inorg. Chem, 2004, 43, 4663-73;

[16]. Prenesti E., Berto S., Daniele P.G., Spectrochimica Acta Part A 59, 2003, 201-207;

[17]. Batiu C., Jelic C., Leopold N., Cozar O., David L., Journal of Molecular Structure, 2005,

[18]. 744-747, 325-330;

[19]. Massabni A., Corbi P., Melnikov P., J. of Coordination Chem., 2004,Vol.57, No.14, 1225-32 